\title{
Review of the Process of Producing the Motion of the Youth MPs Conference through Creative Thinking Skills
}

\section{Tinjauan Proses Penghasilan Usul Persidangan Ahli Parlimen Belia Melalui Kemahiran Pemikiran Kreatif}

\author{
Nasrul Hakim Salleh ${ }^{1 *}$, Marwan Ismail ${ }^{1}$ \\ ${ }^{1}$ Universiti Malaysia Kelantan, MALAYSIA \\ *Corresponding Author
}

DOI: https://doi.org/10.30880/jstard.2020.02.03.024

Received 30 September 2020; Accepted 30 November 2020; Available online 31 December 2020

\begin{abstract}
Creative thinking skills are the main foundation that needs to be applied among Youth MPs. These thinking skills will help APBM formulate the proposals for debate before being appointed as a youth development policy. In accordance with PBM which serves as a medium for youth leaders to get involved in the process of forming youth development policy. This study uses an in-depth interview method involving 9 informants representing 9 PBM Committees. APBM's creative thinking skills process consists of nine themes namely; knowledge, understanding issues, framework building, information gathering, spirituality, information enlightenment, understanding/clarity of issues, production of proposals, and review of motions. As a result, APBM is able to formulate proposals to be debated in the PBM conference.
\end{abstract}

Keywords: Malaysian Youth Parliament, creative thinking, youth development, themes

\begin{abstract}
Abstrak: Kemahiran pemikiran kreatif merupakan asas utama yang perlu diterapkan dalam kalangan Ahli Parlimen Belia. Kemahiran pemikiran tersebut akan membantu APBM merangka usul-usul perbahasan sebelum diangkat menjadi dasar pembangunan belia. Sesuai dengan PBM yang berfungsi sebagai medium untuk pemimpin belia melibatkan diri dalam proses pembentukan dasar pembangunan belia. Kajian ini menggunakan kaedah temubual mendalam yang melibatkan 9 orang informan yang mewakili 9 Jawatankuasa PBM. Proses kemahiran pemikiran kreatif APBM terdiri daripada sembilan tema iaitu; berpengetahuan, memahami isu, membina rangka, pengumpulan maklumat, kerohanian, pencerahan maklumat, kefahaman / kejelasan isu, penghasilan usul dan semakan usul. Impaknya, APBM berupaya merangka usul-usul untuk dibahaskan dalam persidangan PBM.
\end{abstract}

Kata Kunci: Parlimen Belia Malaysia, pemikiran kreatif, pembangunan belia, tema

\section{Pengenalan}

Pembangunan belia digambarkan sebagai satu proses yang berterusan untuk memenuhi keperluan fizikal dan tuntutan sosial dalam membina kompetensi belia (Delgado, 2002). Pembangunan belia yang berstruktur dan mampan adalah penting untuk meneruskan agenda masa depan negara (Mohd Mursyid Arshad et al. 2015). Penubuhan Parlimen Belia Malaysia (PBM) merupakan inisiatif kerajaan untuk melahirkan pemimpin pelapis melalui penglibatan belia 
dalam proses kepimpinan. PBM menjadi medium untuk pemimpin belia mengasah bakat dan menambah ilmu kepimpinan.

\section{Sorotan Karya \\ Pembangunan Belia}

Kerajaan telah memainkan peranan yang besar untuk membangunkan belia daripada pelbagai aspek. Langkah proaktif pembangunan belia Malaysia bermula melalui penggubalan Akta Pertubuhan Belia dan Pembangunan Belia 2007 (Akta 668). Akta tersebut berperanan memastikan pertubuhan-pertubuhan belia di Malaysia didaftarkan, menggalakkan dan memudahkan proses pembangunan belia di Malaysia daripada aspek pendidikan, penyelidikan dan pembangunan sumber manusia. Penggubalan Akta 668 telah mewujudkan dua agensi utama kerajaan iaitu Institut Penyelidikan Pembangunan Belia Malaysia (IYRES) dan Pejabat Pendaftar Pertubuhan Belia (ROY) yang berperanan dalam aspek penyelidikan pembangunan belia dan bertindak sebagai badan urus tadbir persatuan-persatuan belia di Malaysia (Mohd Uzaini, 2018). Pembangunan belia di Malaysia bermula dengan pengubalan Dasar Pembangunan Belia 1985, Dasar Pembangunan Belia Negara 1997 dan Dasar Belia Malaysia 2015.

\section{Parlimen Belia Malaysia}

Parlimen Belia Malaysia (PBM) ditubuhkan sebagai platform kepada belia untuk berbincang dan memberi pandangan agar pemerkasaan belia dapat dicapai. Menurut Kementerian Belia dan Sukan Malaysia (2015) Parlimen Belia Malaysia berperanan sebagai platform untuk belia menyuarakan idea dan pandangan. Perlaksanaan Parlimen Belia Malaysia (PBM) ini hampir menyamai Parlimen Belia di 33 buah negara seperti kebanyakan negara-negara maju dan membangun seperti Australia, United Kingdom, New Zealand, Timor Leste, Filipina, Bangladesh dan di beberapa Negara Eropah. Berdasarkan jumlah persatuan belia yang berdaftar dengan Pejabat Pendaftar Pertubuhan Belia Malaysia (ROY) hanya 20\% (peratus) daripada populasi belia Malaysia terlibat dalam persatuan belia (Mohd Uzaini, 2017). Proses pemilihan APBM dilakukan sepenuhnya mengunakan kaedah atas talian. Secara spesifik, objektif PBM adalah seperti berikut: i. meningkatkan pengetahuan dan kemahiran kepimpinan di kalangan generasi Y demi penerusan kepimpinan negara jangka panjang;ii. sebagai pendedahan kepada belia bagaimana proses undang-undang dibuat serta memahami sistem pentadbiran negara; dan iii. mengenal pasti trend belia untuk disesuaikan dengan pembentukan polisi pentadbiran Negara.

\section{Kemahiran Pemikiran Kreatif}

Kemahiran pemikiran kreatif merupakan aspek penting dalam kepimpinan (Charalampos et al, 2015) kerana pemimpin bertanggungjawab menilai, menapis dan menjana idea baharu (Mainnemelis, 2010). Pemimpin yang gagal menguasai kemahiran pemikiran tersebut akan menghadapi kesukaran untuk melakukan penilaian idea (Mumford et al, 2014). Kajian terkini menunjukkan kemahiran pemikiran kreatif menjadi keperluan utama kepada pemimpin untuk memastikan masa depan institusi yang dipimpin mereka terus mampan (Tierney, 2008; Lingo \& O`Mahony, 2010). Pemimpin yang berfikiran kreatif mempunyai tingkah laku yang unik, sentiasa mempunyai idea yang berlainan dengan cara tradisional (Myer \& Ligon, 2011). Pembaharuan institusi lahir daripada pemimpin yang berpemikiran kreatif (Charalampos et al, 2015). Kemahiran pemikiran kreatif membantu pemimpin belia melakukan penilaiaan idea yang lebih baik melalui pengabungan, penjanaan dan penelitian semula idea (Mumford, 2002). Kemahiran kreatif merupakan komponen penting kepada pemimpin kerana kemahiran tersebut membantu menjana idea yang akan diikuti oleh orang lain (Sternberg, 2003). Illies (2004) menyatakan kemahiran pemikiran kreatif diperlukan oleh pemimpin untuk merangsang pemikiran kreatif, berkemampuan menyelesaikan masalah, menyelaraskan proses organisasi untuk mencapai matlamat yang ditetapkan. Perkara tersebut selari dengan pandangan Byrne et al (2010) dan Mumford et al (2014) yang menyatakan bahawa pemimpin kreatif mempunyai kemahiran perancangan yang strategik. Mainemelis (2010) menyatakan konsep pemikiran kreatif mengandungi dua aspek iaitu proses dan produk. Noor Hisham (2014) menyatakan lazimnya konsep pemikiran kreatif berkisar kepada entiti tertentu iaitu ; Melakukan sesuatu dengan cara yang unik ; seseorang itu dapat keluar daripada pola yang sama ;berfikir di luar kotak; melihat sesuatu daripada perspektif baharu; menggabungkan idea yang sedia ada kepada pembentukan idea baharu; membuka minda dengan idea-idea baharu; mancabar andaian; mencipta sesuatu yang baharu; menghubungkan idea yang tidak berkaitan ; menerbitkan idea besar kepada idea-idea kecil ; berfikir secara fleksibel ; penghasilan idea, penyelesaian, konsep dan produk yang asli (novel); membuat sintesis, imaginasi dan visualisasi

\section{Metodologi}

Kajian ini menggunakan kaedah temubual mendalam melibatkan 9 orang informan yang mewakili sembilan Jawatankuasa Parlimen Belia Malaysia. Secara keseluruhan terdapat serama138 orang Ahli Parlimen Belia. 122 APBM dipilih melalui pilihanraya atas atas talian, manakala seramai 16 orang APBM adalah melalui lantikan Menteri. 
Pemilihan informan adalah berdasarkan kriteria iaitu; terpilih melalui pilihanraya PBM yang dilakukan secara atas talian dan memegang jawatan sebagai pengerusi atau setiausaha Jawatankuasa PBM.

\section{Rajah 1 - Taburan Responden Mengikut Jawatankuasa PBM}

\begin{tabular}{lll}
\hline Bil & Jawatankuasa & Jawatan \\
\hline $\mathbf{1}$ & Sosio Ekonomi & Pengerusi \\
\hline $\mathbf{2}$ & Hubungan Antarabangsa Dan Diplomatik & Pengerusi \\
\hline $\mathbf{3}$ & $\begin{array}{l}\text { Keselamatan, Undang-Undang Dan } \\
\text { Integriti }\end{array}$ & Pengerusi \\
\hline $\mathbf{4}$ & Pendidikan Dan Kerjaya & Pengerusi \\
\hline $\mathbf{6}$ & Kerohanian Dan Keagamaan & Pengerusi \\
\hline $\mathbf{6}$ & $\begin{array}{l}\text { Kebudayaan, Sukan, Patriotisme Dan } \\
\text { Integrasi }\end{array}$ & Setiausaha \\
\hline $\mathbf{8}$ & Prasana, Pembangunan Dan Alam Sekitar & Pengerusi \\
\hline $\mathbf{9}$ & Pembangunan Masyarakat Dan Kesihatan & Pengerusi \\
\hline
\end{tabular}

\section{Dapatan Kajian}

Analisis kajian menunjukkan proses pemikiran kreatif APBM terdiri daripada sembilan tema utama iaitu ; berpengetahuan, memahami isu, membina rangka, pengumpulan maklumat, kerohanian, pencerahan maklumat, kefahaman/kejelasan isu,penghasilan usul dan semakan usul. Manakala proses penghasilan usul perbahasan PBM melibatkan empat subtema iaitu objektif usul, kepentingan usul, usul mewakili suara belia dan kesan usul.

\section{Penghasilan Usul}

Kajian menunjukkan antara tema utama yang penting ialah penghasilan usul. Informan akan melakukan proses penghasilan usul setelah melalui persediaan (berpengetahuan, memahami isu, membina rangka, pengumpulan maklumat, kerohanian, pencerahan maklumat, kefahaman/kejelasan isu) yang rapi. Tahap persediaan merupakan asas utama dalam proses pemikiran kreatif (Kekang He, 2017). Dapatan menunjukan dalam tema penghasilan usul terdapat empat sub tema utama iaitu : objektif usul, kepentingan usul, usul mewakili suara belia dan kesan usul.

“.......bagi saya sebelum sesuatu usul dilakukan banyak perkara yang perlu clear dahulu. Kalau dalam kata mudah preparation is must. Tidak boleh tiba-tiba sahaja ada usul. Perlu ada proses dia" (IN4)

\section{a) Objektif Usul}

Analisis temubual mendalam menunjukan informan akan menetap objektif tertentu sebelum merangka sesuatu usul. Menurut informan, penetapan objektif usul membantu memudahkan penghasilan usul dan mengelakkan berlaku kesilapan dalam penghasilan usul.

“.....biasanya kami akan tetapkan dahulu objektif sebelum rangka usul. Apa objektif yang kita mahu capai dengan usul itu. Perlu ada penanda yang jelas. Ini akan membantu meudahkan kami hasilkan usul. Contoh objektif usul mahu selesaikan masalah pemilikan rumah dalam kalangan belia. Usul yang dikemukan mesti berkaitan dengan isu tersebut" (IN7)

\section{b) Kepentingan Usul (Belia, Masyarakat Kerajaan)}

Informan turut menyatakan bahawa aspek kepentingan usul turut diambil kira dalam proses penghasilan usul. Data mendapati informan mengambil kira kepentingan usul daripada sudut belia, masarakat dan kerajaan. Usul yang dihasilkan mampu membantu belia sekaligus turut menyumbang kepada pembangunan masyarakat dan berupaya memajukan negara.

"Sejauh mana penting usul itu selalu saya fikirkan. Saya suka guna istilah tiga serangkai..kepentingan kepada belia, masyarakat dan negara. Kalau penting untuk belia sahaja pun tidak boleh. Mesti penting untuk semua.....contoh isu pendidikan seks. Usul itu dibahaskan di PBM. Diluluskan. Bawa kepada kerajaan. Alhamdulillah kerajaan sambut baik" (IN9) 
“....usul berkaitan pendidikan seks itu antara kejayaan PBM yang diakui kerajaan. Kerana usul itu ada manfaat kepada masyarakat. Kepentingan kepada belia tu tidak perlu cerita lah. Sangat penting” (IN1)

\section{c) Usul mesti mewakili suara belia (tiada campur tangan pihak tertentu)}

Kajian juga mendapati infoman akan memastikan sesuatu usul yang dihasilkan mewakili suara belia. Unsur-unsur campur tangan politik akan dielakan demi memastikan APBM tidak menjadi alat politik kepada mana-mana pihak. Informan menegaskan bahawa dalam PBM politik kepartian tidak diamalkan. Sebaliknya setiap APBM bertindak sebagai wakil belia untuk menyampaikan suara kepada kerajaan. Menurut informan, usul yang mempunyai kepentingan politik akan ditolak dalam peringkat Jawatankuasa PBM lagi.

"Usul yang akan dirangka mesti mewakili suara belia....tujuan utama PBM pun...kami sebagai APBM bertindak sebagai orang tengah menyampaikan suara akar umbi kepada kerajaan. Untuk bantu kerajaan rangka dasar yang bersesuain untuk pembangunan belia Kalau buat usul pasal ada kepentingan politik atau campur tangan pihak tertentu tu...saya rasa tidak patut. Sudah lari dari tujuan asal PBM" (IN5)

\section{d) Kesan usul (jangka masa pendek / panjang)}

Kajian mendapati informan turut mengambil berat aspek kesan atau impak usul yang dirangka. Kesan usul dilihat daripada sudut jangka masa pendek dan panjang. Informan akan menimbangkan kedua-dua kesan jangka pendek dan panjang sesuatu usul dalam penggubalan usul. Informan menyatakan mereka memahami hasrat golongan belia yang menuntut penyelesaian segera kepada sesuatu isu dan mempersoalkan dasar yang diperkenalkan kerajaan. Informan menyatakan perkara tersebut terjadi kerana setiap dasar kerajaan mempunyai kesan jangka pendek dan pajang.

“....mahu rangka usul ni bukan perkara mudah. Antara aspek yang perlu dilihat ialah kesan usul itu sendiri. Kesan jangka pendek...kesan jangka panjang. Kadang-kadang orang muda ni, mereka mahukan penyelesaian segera. Misalnya kerajaan buat sesuatu dasar dan dasar itu bersifat jangka panjang...isu tidak selesai segera. Orang muda tidak faham kerana dasar itu bersifat perancangan jangka panjang. Kerana itu saya sebut kesan jangka pendek dan panjang usul itu kena kita teliti dahulu" (IN8).

\section{Kesimpulan}

Berdasarkan kajian, didapati APBM menunjukkan kesungguhan untuk membantu kerajaan merangka dasar pembangunan belia dengan mecadangkan beberapa usul untuk pertimbangan kerajaan. Pengubalan usul yang berkualiti memerlukan kepada proses kemahiran pemikiran kreatif. Kesemua informan menunjukkan bahawa mereka mengikuti langkah-langkah proses pemikiran kreatif sebelum merangka sesuatu usul. Penghasilan usul yang bermutu akan meningkatkan nilai penglibatan pemimpin belia dalam membantu kerajaan merangka dasar pembangunan belia.

\section{Penghargaan}

Penulis ingin mengucapkan terima kasih kepada Universiti Malaysia Kelantan atas bantuan dan maklumat yang diberikan untuk memastikan kejayaan kajian ini.

\section{Rujukan}

[1] Byrne, C. L., Shipman, A. S., \& Mumford, M. D 2010 The effects of forecasting on creative problem solving: An experimental study Creativity Research Journal 22, 119-138

[2] Charalampos Mainemelis, Ronit Kark, Olga Epitropaki 2015 Creative Leadership: A Multi-Context Conceptualization The Academy of Management Annals Vol. 9, No. 1, 393-482

[3] Delgado, M 2002 New frontiers foryouth development in the twenty-first century revitalizingyouth development New York: Columbia University Press

[4] Hunter, S. T., Thoroughgood, C. N., Myer, A. T., \& Ligon, G. S. 2011 Paradoxes of leading innovative endeavors: Summary, solutions, and future directions. Psychology of Aesthetics, Creativity, and the Arts, 5(1), $54-66$

[5] llies, J. J., \& Reiter-Palmon, R 2004 The effects of type and level ofpersonal involvement on information search and problem solving Journal of Applied Social Psychology 34, 1709 -1729

[6] Kekang He 2017 A Theory of Creative Thinking: Construction and Verification of the Dual Circulation Model Springer Publishing Company, Incorporated

[7] Lingo, E. L., \& O’Mahony, S 2010 Nexus work: Brokerage on creative projects Administrative Science Quarterly

[8] Mainemelis, C 2010 Stealing fire: Creative deviance in the evolution of new ideas Academy of Management Review 35, 558-578 
[9] Mohd Mursyid Arshad, Othman Jailani, David M. Rosch, Ismi Arif Ismail, \& Kalthom Abu Bakar 2018 Pembangunan Belia Positif Menerusi Proses Pementoran Kepada Pembangunan Kepemimpinan Pelajar Kolej Kediaman Universiti Awam Di Malaysia Prosiding Konvensyen Kepengetuaan dan Felo Penghuni Kolej Kediaman Universiti Awam Kebangsaan 2018 ISBN:e978-967-0829-97-5

[10] Mohd Uzaini Mohamad Sani \& Suhana Saad 2018 Perlaksanaan dan cabaran penglibatan belia dalam parlimen belia Malaysia Journal of Social Sciences and Humanities Vol.13 No.1 (2018)

[11] Mumford, M. D., Gibson, C., Giorgini, V., \& Mecca, J. 2014 Leading for creativity: People, products, and systems. In D. Day (Ed.), The Oxford handbook of leadership and organizations (pp. 754-779). New York, NY: Oxford University Press

[12] Noor Hisham Md. Nawi 2014 Sinergisme Pemikiran Islam Kritis Kreatif Penerbit Universiti Malaysia Kelantan, Kelantan

[13] Sternberg, R. J 2003 WICS: A model of leadership in organizations. Academy of Management Learning \& Education, 2, 386-401

[14] Tierney, W. G 2008 The impact of culture on organizational decision making Sterling VA Stylus 